\title{
Significance of idiopathic deep venous thrombosis
}

\author{
N. T. J. O'CONNOR \\ M.R.C.P.
}

E. W. FLETCHER

F.R.C.R.

\author{
S. A. CEDERHolm-Williams \\ D.Phil.
}

\author{
M. Allington
}

D.Phil.

\author{
A. A. SHARP \\ F.R.C.P., F.R.C.Path.
}

Departments of Haematology and Radiology, John Radcliffe Hospital, Headington, Oxford OX3 9DU

\begin{abstract}
Summary
The risk of developing an overt malignancy after an isolated deep venous thrombosis (DVT) is poorly documented. We therefore reviewed a series of patients in whom a solitary idiopathic DVT had been proven by venography at least 12 months earlier. No patient had developed a malignancy at follow-up. However, decreased fibrinolytic activity was observed in five out of the six patients aged less than $\mathbf{4 5}$ years. Patients with an idiopathic DVT should not be subjected to an exhaustive search for malignancy.
\end{abstract}

KEY WORDS: malignancy, fibrinolysis, blood group.

\section{Introduction}

Ten percent of patients with deep venous thrombosis (DVT) of the lower limb have no apparent precipitating cause (Anylan, Shingleton and Delaughter, 1956). Since DVT is a recognized complication of malignancy, many authors recommend an extensive clinical and radiological investigation for occult malignancy in such patients although the extent of the risk of developing overt neoplasia has not been defined (Sack, Levin and Bell, 1977). We therefore reviewed all patients who had suffered an idiopathic DVT over a 2-year period at our hospital.

\section{Patients and methods}

Venography is the investigation of choice for an unexplained swollen leg and is readily available at our hospital. Therefore venographic evidence of a DVT was an essential criterion for entry to the study, and we reviewed all the 345 venograms performed between August 1979 and September 1981. DVT was shown in 127 patients and notes of all these patients were reviewed to ascertain whether a precipitating cause had been found. This identified a group of 17 patients who had suffered an idiopathic DVT.

These patients formed the study population and, except for two patients who had died, were all reviewed. Patients were seen at between 12 and 38 months after initial diagnosis (mean 23 months). All patients were examined and blood was taken for Coulter blood count, blood grouping, coagulation tests, antithrombin III (ATIII) activity and platelet aggregometry (Dacie and Lewis, 1975), with results being compared to established laboratory controls. In addition plasminogen activator levels were assayed before and after venous occlusion in both the patients and a group of normal subjects aged less than 45 years (Robertson, Pandolfi and Nilsson, 1972).

\section{Results}

Over a 26-month period, 127 patients had a venographically proven DVT at our hospital. Precipitating factors were identified in 110 patients as shown in Table 1 . Thus 17 patients had suffered an idiopathic DVT and details of these patients are summarized in Table 2 . Only one of the nine patients under 70 years of age had a right-sided thrombosis. Two of the 17 patients with idiopathic DVT had died: one an 85-year-old lady had a brainstem stroke 2 months after stopping warfarin and the other, a 57year-old man had a fatal myocardial infarction 12 months after the initial episode. In the 15 patients alive at the time of the study, physical examination was unremarkable. Three patients remain on anticoagulants.

Coulter count, liver function tests, ESR and chest $\mathrm{X}$-ray were normal in all subjects. The results of serological and coagulation tests are summarized in 
TABLE 3. Serological and coagulation tests performed on subjects with a past history of idiopathic DVT

\begin{tabular}{lccccc}
\hline & $\begin{array}{c}\text { Incidence } \\
\text { blood } \\
\text { group 0 }\end{array}$ & $\begin{array}{c}\text { Platelets } \\
\left(10^{\circ} / \mathrm{litre}\right)\end{array}$ & $\begin{array}{c}\text { Fibrinogen } \\
(\mathrm{mg} / \mathrm{dl})\end{array}$ & $\begin{array}{c}\text { Platelet } \\
\text { aggregometry }\end{array}$ & $\begin{array}{c}\text { ATIII } \\
\text { activity } \\
(\%)\end{array}$ \\
\hline Patients & $2 / 15$ & $130-402$ & $179-401$ & Normal & $85-133$ \\
Controls & $6.77 / 15^{*}$ & $150-450$ & $240-395$ & - & $80-120$ \\
\hline
\end{tabular}

*(Mourant, Kipec and Domancewska-Sobzak, 1976).

TABLE 1. Predisposing factors* for DVT in 127 patients with venographic evidence of deep venous thrombosis (1 August 197931 September 1981)

\begin{tabular}{lc}
\hline Predisposing factor & Number of patients \\
\hline Bed rest/immobility & 51 \\
Post operative period & 35 \\
Trauma to leg & 18 \\
Peripheral vascular disease & 14 \\
Pre-existing malignancy & 6 \\
Journey longer than 4 hr & 5 \\
Heart failure & 5 \\
Long history venous disease & 5 \\
Oestrogen treatment & 2 \\
Profound anaemia & 1 \\
Infected ulcer on leg & 1 \\
None found (idiopathic) & 17 \\
\hline
\end{tabular}

*In some patients more than one predisposing factor was identified.

TABLE 2. Age and sex distribution of 17 patients who suffered an idiopathic deep venous thrombosis

\begin{tabular}{lcccc}
\hline & \multicolumn{3}{c}{ Age (years) } & \\
\cline { 2 - 4 } & $25-45$ & $46-70$ & $>71$ & Total \\
\hline Male & 5 & 2 & 4 & 11 \\
Female & 1 & 1 & 4 & 6 \\
\hline
\end{tabular}

Table 3. Fibrinolytic function, as judged by plasminogen activator levels before and after venous occlusion, is shown in Fig. 1 for patients aged $<45$ years, aged $>45$ years and for normal subjects aged $<45$ years.

\section{Discussion}

To our knowledge, no series of patients with proven idiopathic DVT has been previously reported. In our study, venography was obligatory for the diagnosis of DVT, as it provides an accurate and objective assessment (Browse, 1978).

Idiopathic DVT was commoner in males than females and only one patient under 70 years of age had a right-sided DVT. A tendency for DVT to be left-sided has been noted in at least one series of patients with DVT, irrespective of aetiology (Nylan-
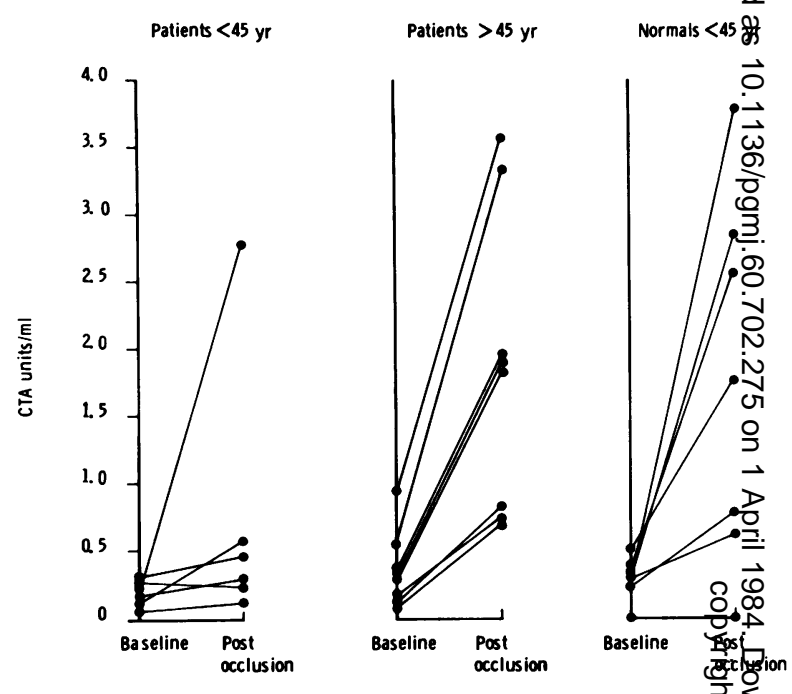

FIG. 1. Plasminogen activator levels (before and after veñou occlusion) in subjects who had suffered an idiopathic DVT and normals.

der and Olivecroria, 1976). This effect is probab more obvious in the young patients with idiopathig DVT, because patients who had suffered trauma to lower limb or were resting post-operatively were excluded from our study. The finding might be explained by the relative venous stasis resulting from compression of the left iliac vein by the right common iliac artery. It is also of note that the incidence of blood group 0 in our patients wa significantly less than expected $(P<0.05)$ : which compatible with the suggestion that blood group 0 is protective against DVT (Jick and Porter, 1978).

Idiopathic DVT is uncommon although it has often been suggested that thrombosis could be precipitated by an increase in blood coagulability on by decreased fibrinolysis (Astrup, 1956). Coagulationo studies were normal in all our subjects, as was ATIA activity. However the poor plasminogen activatof release in response to venous occlusion in five of the six patients aged under 45 years (Fig. 1) suggests th defective fibrinolysis may have a significant role the causation of idiopathic DVT affecting young people. 
Six patients diagnosed as suffering from DVT over the 26-month study period also had an underlying malignancy (Table 1). In all six the thrombotic episode supervened on a previously diagnosed malignancy with five patients being in the immediate postoperative period. In no case had the DVT been the initial complaint which led to the discovery of an underlying malignancy. Further no patient with an idiopathic DVT had developed an overt malignancy by the time of our review, carried out a mean of 23 months after the initial episode.

Review of the literature suggests that patients who suffer a thrombosis as the presenting feature of a malignancy have advanced disease and diagnosis of the underlying condition is not difficult (Anylan, Shingleton and Delaughter, 1956; Sack, Levin and Bell, 1977). Although there are some case reports of idiopathic DVT antedating the diagnosis of malignancy; it is very rare for the DVT to precede the discovery of the underlying condition by more than a few weeks and there is no proof that such events are more than mere coincidence. Therefore we conclude that a patient with an idiopathic DVT should not be subjected to an exhaustive search for underlying malignancy.

\section{Acknowledgment}

This work was supported by a grant from the Oxford District Research Committee.
We regret that Dr. A. A. Sharp died before publication of this article.

\section{References}

Anylan, W.G., Shingleton, W.W. \& Delaughter, G.D. (1956) Significance of idiopathic venous thrombosis and hidden cancer. Journal of the American Medical Association. 161, 964.

ASTRUP, H. (1956) The biological significance of fibrinolysis. Lancet, ii, 565 .

BRowSE, N.L. (1978) Diagnosis of deep venous thrombosis. British Medical Bulletin, 34, 163.

Dacie, J.V. \& LeWIS, S.M. (1975) Practical Haematology. Churchill Livingstone, Edinburgh.

JICK, H. \& PORTER, J. (1978) Thrombophlebitis of the lower extremities and ABO blood type. Archives of Internal Medicine. 138, 1566.

Mourant, A.E., KipeC, A.C. \& Domancewska-SobCZaK, K. (1976) The Distribution of Human Blood Groups, p. 172. Oxford Medical Publications.

Nylander, G. \& Olivecroria, H. (1976) The phlebographic pattern of acute leg thrombosis within a defined urban population. Acta Chiropractica Scandinavica, 142, 505.

Robertson, B.R., Pandolfi, M. \& Nilsson, I.M. (1972) Fibrinolytic activity in healthy volunteers at different ages as measured by standardised venous occlusion of arms and legs. Acta Medica Scandinavica, 191, 199.

SACK, G.H., LEVIN, J. \& BELL, W.R. (1977) Trousseau's syndrome and other manifestations of chronic disseminated coagulopathy in patients with neoplasms: clinical, pathophysiological and therapeutic features. Medicine, 6, 1 .

(Accepted 12 July 1983) 